\title{
Expression profiles of two small heat shock proteins and antioxidant enzyme activity in Mytilus galloprovincialis exposed to cadmium at environmentally relevant concentrations*
}

\author{
YOU Liping (由丽萍 $)^{1,3}$, NING Xuanxuan (宁璇璇 $)^{2}$, CHEN Leilei (陈磊否) $)^{1}$, \\ ZHANG Linbao (张林宝 $)^{1}$, ZHAO Jianmin (赵建民 $)^{1, * *}$, LIU Xiaoli (刘小莉) $)^{1,2}$, \\ WU Huifeng (吴惠丰) $)^{1, * *}$ \\ Key Laboratory of Coastal Zone Environmental Processes and Ecological Remediation, Yantai Institute of Coastal Zone \\ Research, Chinese Academy of Sciences, Yantai 264003, China \\ ${ }^{2}$ Yantai Oceanic Environmental Monitoring Central Station, State Oceanic Administration, Yantai 264006, China \\ ${ }^{3}$ University of Chinese Academy of Sciences, Beijing 100049, China
}

Received Mar. 20, 2013; accepted in principle May 29, 2013; accepted for publication Aug. 1, 2013

(C) Chinese Society for Oceanology and Limnology, Science Press, and Springer-Verlag Berlin Heidelberg 2014

\begin{abstract}
Small heat shock proteins encompass a widespread but diverse class of proteins, which play key roles in protecting organisms from various stressors. In the present study, the full-length cDNAs of two small heat shock proteins (MgsHSP22 and MgsHSP24.1) were cloned from Mytilus galloprovincialis, which encoded peptides of 181 and 247 amino acids, respectively. Both MgsHSP22 and MgsHSP24.1 were detected in all tissues examined by real-time PCR, with the highest expression being observed in muscle and gonad tissues. The real-time PCR results revealed that Cd significantly inhibited MgsHSP22 expression at $24 \mathrm{~h}$ and MgsHSP24.1 at 24 and $48 \mathrm{~h}$ under $5 \mu \mathrm{g} / \mathrm{L} \mathrm{Cd}^{2+}$ exposure. MgsHSP24.1 expression was also significantly inhibited after $50 \mu \mathrm{g} / \mathrm{L} \mathrm{Cd}^{2+}$ exposure for $48 \mathrm{~h}$. With regard to antioxidant enzymes, increased GPx and CAT activity were detected under $\mathrm{Cd}^{2+}$ stress $(5$ and $50 \mu \mathrm{g} / \mathrm{L})$, while no significant difference in SOD activity was observed throughout the experiment. Overall, both MgsHsps and antioxidant enzymes revealed their potential as $\mathrm{Cd}$ stress biomarkers in M. galloprovincialis.
\end{abstract}

Keyword: Mytilus galloprovincialis; small heat shock protein; superoxide dismutase (SOD); catalase (CAT); glutathione peroxidase (GPx); cadmium

\section{INTRODUCTION}

Over the past few decades, heavy metal contamination has been of great concern in marine and coastal ecotoxicology (Pipe and Coles, 1995; Haslbeck, 2002; Järup, 2003; Liu et al., 2011). Among the heavy metals, cadmium $(\mathrm{Cd})$ is considered an important toxicant accumulated by many marine organisms (Roccheri et al., 2004). It can cause a series of detrimental effects to the organisms, such as production of reactive oxygen species (ROS), depletion of glutathione, and inhibition of enzymes involved in DNA synthesis and repair (Waisberg et al., 2003; Roccheri et al., 2004).

The rapid elimination of excessive ROS induced by $\mathrm{Cd}$ is essential for the organisms. The primary defense against oxidative damage consists of the major antioxidant enzymes, e.g. superoxide dismutase (SOD), catalase (CAT), and glutathione peroxidase (GPx) and some low-molecular weight compounds (vitamins A, C, and uric acid) (Orbea et al., 2000). These antioxidant enzymes can act as effective free radical scavengers in response to oxidative stress, and

\footnotetext{
* Supported by the 100 Talents Program of the Chinese Academy of Sciences, the National Natural Science Foundation of China (No. 41206105), and the Key Deployment Program of Chinese Academy of Sciences (No. KZZD-EW-14-03)

** Corresponding authors: jmzhao@yic.ac.cn; hfwu@yic.ac.cn
} 
they have also been proposed as biomarkers of environmental contaminants (Richardson et al., 2008; Jena et al., 2009).

Living organisms usually synthesize a small number of highly conserved proteins called heat shock proteins (HSPs) in response to different environment stressors (Lindquist, 1986). HSPs are a family of proteins that enhance cell survival under the influence of various stressors including hyperthermia, heavy metals, and oxidants, among others. In ecotoxicology, HSPs have been widely used as biomarkers of environmental pollutants (Lewis et al., 1999). There are several HSP families based on their molecular mass and function, these include HSP100, HSP90, HSP70, HSP60, and the small HSPs (sHsps) (Trent, 1996). The sHsps are composed of a conserved $\alpha$-crystallin domain with molecular weights ranging from $12-43 \mathrm{kDa}$ (Franck et al., 2004; Sun et al., 2005). sHsps are essential in protecting cells from various stresses, facilitating the formation and structure of proteins, and maintaining the balance between cell survival and cell death (Gusev et al., 2002; Haslbeck, 2002). For example, the bay scallop, Argopecten irradians, sHSP22 transcript was up-regulated after $\mathrm{Cd}$ exposure for 10 days (Zhang et al., 2010). sHsps also participate in toxic (Cd) resistance mechanisms in amphipod species (Shatilina et al., 2010). However, sHsp responses to heat shock and contamination have been more extensively studied in mammals and insects than in marine organisms (Klemenz and Gehring, 1986; Benndorf et al., 2001; Chowdary et al., 2004). More recently, experimental evidence has suggested that an interrelationship between sHsps and redox status exists. For example, Drosophila HSP27 and murine HSP25 modulate oxidative stress-induced cell death (Arrigo, 2001). It was suggested that sHsps might protect against the deleterious effects induced by oxidative stress through modulating the intracellular redox state (Arrigo, 2002).

Mytilus galloprovincialis are ubiquitous coastal and estuarine filter-feeders and can accumulate higher levels of heavy metals than other species, and have thus been frequently used as bioindicators in environmental monitoring programs (Kavun et al., 2002). In the present study, we aimed to clone the full-length sHSP22 and sHSP24.1 cDNAs from $M$. galloprovincialis, and investigate their temporal expression and the variation of antioxidant enzyme activity in response to $\mathrm{Cd}$ exposure, to provide more information about the modulatory system that responds to heavy metal stress in M. galloprovincialis.

\section{MATERIAL AND METHOD}

\subsection{Mussels and treatments}

M. galloprovincialis (shell length $6.5-7.5 \mathrm{~cm}$ ) were purchased from a local aquaculture farm and acclimated for 10 days prior to the experiment. The sea water was aerated continuously and salinity and temperature maintained at 33 and $17^{\circ} \mathrm{C}$ throughout the experiment. Mussels were fed with Chrysophyta and Tetraselmis chuii, and seawater was renewed daily. After 10 days' acclimatization, the mussels were divided into nine groups and cultivated in 30-L aquarium tanks, each containing 25 individuals. Six tanks of mussels (three replicates for each treatment) were exposed to environmentally relevant concentrations of $\mathrm{Cd}^{2+}\left(5\right.$ and $50 \mu \mathrm{g} / \mathrm{L} \mathrm{Cd}^{2+}$, prepared from $\mathrm{CdCl}_{2}$ ). The $\mathrm{Cd}$ concentrations applied have been previously reported in some heavily polluted sites in the Bohai Sea (Zhang et al., 2001). Mussels cultured in filtered, uncontaminated seawater served as the control group. The toxicant-laden seawater was renewed daily and $\mathrm{CdCl}_{2}$ was added. The hepatopancreas of six individuals from each treatment and the control were sampled at each time interval $(0$, 24, 72, and $96 \mathrm{~h}$ after $\mathrm{Cd}$ exposure), and then divided into two parts: one for antioxidant enzyme assay and the other for total RNA extraction. The tissues, including the hepatopancreas, hemocytes, muscle, gonad, gills, and mantle, were dissected from six individuals as parallel samples and subjected to total RNA extraction with TRIzol ${ }^{\mathbb{}}$ reagent (Invitrogen).

\subsection{Full-length MgsHSP22 and MgsHSP24.1 cDNA cloning}

Two ESTs, highly similar to previously identified sHSP22 and sHSP24.1, were identified from the $M$. galloprovincialis cDNA library. The MgsHSP22 and MgsHSP24.1 3' and 5' ends were obtained by nested PCR. The PCR products were gel-purified and subcloned into the pMD18-T Simple Vector (TaKaRa, Japan). After being transformed into Escherichia coli Top10F' competent cells, three positive clones for each sHsp were sequenced bi-directionally with the primers M13-47 and RV-M (Table 1).

\subsection{Sequence analysis}

The nucleotide and protein sequence analyses were performed with the BLAST algorithm at the National Centre for Biotechnology Information (http://www. ncbi.nlm.nih.gov/blast). The deduced amino acid 
Table 1 Primers used in the present study

\begin{tabular}{ccc}
\hline Primers & Sequence (5'-3') & Sequence information \\
\hline F1 (forward) & CGAACTAAATAAGCCAGCA & RT primer for MgsHSP22 \\
R1 (reverse) & TGCTGGCTTATTTAGTTCG & RT primer for MgsHSP22 \\
F2 (forward) & GGTGCCTTAGTGTCAAGTGATAGT & RT primer for MgsHSP24.1 \\
R2 (reverse) & AGATCGTGGAACTGTCATCTGAC & RT primer for MgsHSP24.1 \\
Mg-F (forward) & GCTATCCAGGCCGTACTCT & $\beta$-actin primer \\
Mg-R (reverse) & GCGGTGGTTGTGAATGAG & $\beta$-actin primer \\
M13-47 & CGCCAGGGTTTTCCCAGTCACGAC & Sequencing primer \\
RV-M & GAGCGGATAACAATTTCACACAGG & Sequencing primer
\end{tabular}

sequences were analyzed with the Expert Protein Analysis System (http://www.expasy.org/). Multiple sHsp alignments were performed using the ClustalW Multiple Alignment Program (http://www.ebi.ac.uk/ clustalw/), and signal peptides were predicted with SignalP 3.0. Two phylogenetic trees were constructed with Mega4.1 using the neighbor-joining method. Bootstrap trials were replicated 1000 times to test the relative support for the phylogeny analysis.

\subsection{Quantification analysis of mRNA expression post $\mathrm{Cd}$ exposure}

MgsHSP22 and MgsHSP24.1 expression levels in the hepatopancreas after $\mathrm{Cd}$ exposure were measured by quantitative real-time RT-PCR. The RNA extraction and cDNA synthesis were conducted as per Zhang et al. (2011). The gene-specific primers, F1 and R1 for MgsHSP22 and F2 and R2 for MgsHSP24.1, and the internal control primers, $\mathrm{Mg}-\mathrm{F}$ and $\mathrm{Mg}-\mathrm{R}$ for $\beta$-actin (Wang et al., 2010), are listed in Table 1. The amplification was performed in a total volume of $50 \mu \mathrm{L}$, containing $25 \mu \mathrm{L}$ of $2 \times \mathrm{SYBR}^{\circledR}$ Green Master Mix (Applied Biosystems), $4 \mu \mathrm{L}$ of the $50 \times$ diluted cDNA mix, $1 \mu \mathrm{L}$ (each) of the forward and reverse primers $(10 \mu \mathrm{mol} / \mathrm{L})$, and $19 \mu \mathrm{L}$ of DEPC-treated water. The thermal profile was $50^{\circ} \mathrm{C}$ for $2 \mathrm{~min}$ and $95^{\circ} \mathrm{C}$ for $10 \mathrm{~min}$ followed by 45 cycles of $95^{\circ} \mathrm{C}$ for $15 \mathrm{~s}$ and $60^{\circ} \mathrm{C}$ for $1 \mathrm{~min}$. At the end of each PCR reaction, a dissociation curve analysis of the amplification products was performed to confirm only one PCR product amplified and was detected. To maintain consistency, the baseline was automatically set by SDS (SDS v. 2.3, Applied Biosystems). The relative expression level of both genes was analyzed by the $2^{-\Delta \Delta C t}$ method (Livak and Schmittgen, 2001).

\subsection{Antioxidant enzyme activity assay}

To assay antioxidant enzyme activity, $0.1 \mathrm{~g}$ of hepatopancreas was homogenized in $10 \%(\mathrm{w} / \mathrm{v})$ homogenate medium $(10 \mathrm{mmol} / \mathrm{L}$ Tris- $\mathrm{HCl}$, $0.1 \mathrm{mmol} / \mathrm{L}$ EDTA-Na, $10 \mathrm{mmol} / \mathrm{L}$ sucrose, and $0.8 \% \mathrm{NaCl}$ solution, $\mathrm{pH}$ 7.4) using an IKA homogenizer (Ultra Turrax IKA T10 basic, Staufen, Germany). The homogenates were centrifuged $(425 \times g)$ for $15 \mathrm{~min}$ at $4^{\circ} \mathrm{C}$ to harvest the supernatant and subjected to an antioxidant enzyme assay. GPx, SOD, and CAT activity were measured according to the manufacturer's protocols (Jiancheng, China). The total protein concentration of the supernatant was measured according to Bradford (1976) using bovine serum albumin (BSA) to normalize enzyme activity data. All enzyme activity is expressed in terms of units per milligram protein, where one unit represents the change in absorbance $/(\mathrm{min} \cdot \mathrm{mg}) /$ protein.

\subsection{Statistical analysis}

The data were normally distributed (Shapiro-Wilk test, $P>0.05$ ). One-way ANOVA with Tukey's test was performed on all data in SPSS 16.0, and $P$-values less than 0.05 were considered statistically significant. All data are given as means $\pm \operatorname{SE}(n=6)$.

\section{RESULT}

\subsection{MgsHSP22 and MgsHSP24.1 sequence analysis}

The complete MgsHSP22 and MgsHSP24.1 cDNA sequences were deposited in GenBank under the accession Nos. JF803804 and JF803805, respectively. The MgsHSP22 and MgsHSP24.1 nucleotide sequences were predicted to encode a polypeptide of 162 and 247 amino acids, respectively (Fig.1). No signal peptide was found in either MgsHSP22 or MgsHSP24.1 by SignalP analysis, which revealed that the deduced proteins were cytosolic sHsps. SMART program analysis indicated the existence of the $\alpha$-crystallin domain in the deduced MgsHSP22 
a

1 ACATTCTACAAACCGGATGCAGAAAGCAGACGATAGTTTTGAAATGTCCAGCCGTATTGT

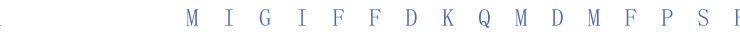
61 TCCAGTTAAGCGTTATGATTGGAATTTTTTTCGACAAGCAAATGGACATGTTCCCATCTT $\begin{array}{lllllllllllllllllllll}7 & K & N & D & F & D & K & D & F & F & K & D & A & K & H & S & S & M & D & E & E\end{array}$ 121 TTAAAAATGATTTCGACAAAGATTTTTTCAAGGATGCCAAGCATTCAAGTATGGATGAAG $\begin{array}{lllllllllllllllllllll}37 & \mathrm{I} & \text { A } & \mathrm{R} & \mathrm{M} & \mathrm{K} & \mathrm{R} & \mathrm{E} & \mathrm{M} & \mathrm{F} & \mathrm{S} & \mathrm{L} & \mathrm{T} & \mathrm{T} & \mathrm{P} & \mathrm{E} & \mathrm{S} & \mathrm{S} & \mathrm{L} & \mathrm{K} & \mathrm{V}\end{array}$ 181 AAATAGCAAGGATGAAACGGGAGATGTTCAGCCTGACAACACCAGAGTCAAGTTTGAAAG

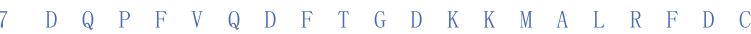
241 TAGATCAACCTTTTGTTCAGGATTTTACTGGAGATAAGAAAATGGCTCTACGGTTTGATT $\begin{array}{lllllllllllllllllllll}77 & \text { S } & \text { Q } & \text { F } & \text { N } & \text { P } & \text { E } & \text { E } & \text { I } & \text { Q } & \text { V } & \text { K } & \text { T } & \text { M } & \text { D } & \text { K } & \text { Q } & \text { L } & \text { T } & \text { V } & \text { H }\end{array}$ 301 GCAGTCAGTTTAATCCTGAGGAAATTCAAGTAAAAACAATGGACAAACAATTAACTGTAC $\begin{array}{lllllllllllllllllllll}97 & \text { A } & K & \text { H } & \text { E } & \text { E } & \text { V } & \text { S } & \text { P } & \text { G } & \text { R } & \text { K } & \text { V } & \text { Y } & \text { R } & \text { E } & \text { F } & \text { T } & \text { K } & \text { S } & \text { Y }\end{array}$ 361 ATGCCAAACATGAAGAAGTTTCACCGGGAAGGAAAGTGTACAGAGAATTCACCAAGTCCT $\begin{array}{lllllllllllllllllllllllllllllllll}117 & \mathrm{~T} & \mathrm{~L} & \mathrm{P} & \mathrm{Q} & \mathrm{D} & V & \mathrm{D} & \mathrm{P} & \mathrm{L} & \mathrm{S} & \mathrm{L} & \mathrm{K} & \mathrm{S} & \mathrm{S} & \mathrm{L} & \mathrm{T} & \mathrm{N} & \mathrm{D} & \mathrm{G} & \mathrm{F}\end{array}$ 421 ACACGTTACCACAGGATGTTGACCCTTTGTCATTGAAGTCCAGCCTGACCAACGACGGAT $\begin{array}{lllllllllllllllllllll}137 & \mathrm{~L} & \mathrm{Q} & \mathrm{V} & \mathrm{E} & \mathrm{A} & \mathrm{P} & \mathrm{A} & \mathrm{P} & \mathrm{K} & \mathrm{T} & \mathrm{C} & \mathrm{V} & \mathrm{A} & \mathrm{R} & \mathrm{K} & \mathrm{E} & \mathrm{I} & \mathrm{F} & \mathrm{I} & \mathrm{P}\end{array}$ 481 TTTTACAAGTTGAAGCTCCTGCACCTAAAACATGTGTCGCAAGGAAGGAAATATTTATTC 157 I $\mathrm{E}$ K

541 CAATTGAGAAAATGCTTAAGTAAATAATTCGAACTAAATAAGCCAGCAAAATGCCAATTA 601 TATATAACATGCTGTGTTGGAAACCATCAGTGAGAAATTATTTTGACCGTTCCGTTTCGA 661 TGAGGCATTACTATTTTGTACAATATCAGAAGAATTTCTTTTGACCGATTCTATGATGAA 721 TTGACATCTATGTACACTTTCAGAGACTTTGGATAGTGCGCAAAATTTGACAATTAATTC 781 AGTATTTTTTGCAGTTTTTAACTATTTTAACAATTTTACATATATGGTTTCGTACTAGCT 841 TTGCATATGTTGTTGTGCATGTTTTGGACTAGCATTCCTGGATCGGTTTCCGTGACAAGA 901 CAATTATTTGAATTCAGTTGTATATGAAAATAAAAAGGTATAAGCAAAAAAAAAAAAAAA $961 \mathrm{AA}$

b

1 GTGGGTGGGAATTAAACGAAATCAACAATACAGACGACTTTTAGCAGAACAGAGTAAAGA $\begin{array}{llllllllllllllllllll}T & F & V & P & V & L & W & N & R & Y & N & Q & S & T & Q & H & D & F & D & D\end{array}$ 61 TGACGTTTGTCCCAGTGCTTTGGAACCGCTACAATCAGTCTACACAGCATGATTTTGATG $\begin{array}{lllllllllllllllllllll}22 & \text { M } & F & H & F & M & D & D & W & E & P & M & S & V & G & Y & G & Y & G & R & H\end{array}$ 121 ACATGTTTCACTTTATGGATGACTGGGAGCCTATGTCCGTAGGTTATGGGTATGGTCGTC

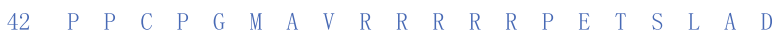
181 ACCCACCATGCCCGGGAATGGCAGTGCGTAGGAGGCGCAGACCGGAGACTTCACTGGCGG $\begin{array}{lllllllllllllllllllll}62 & K & K & W & T & Y & S & V & K & I & G & D & F & D & A & Q & H & V & K & V & K\end{array}$ 241 ATAAAAAGTGGACATACAGCGTAAAATCGGAGACTTTGATGCACAGCATGTCAAAGTGA $\begin{array}{lllllllllllllllllllll}82 & V & D & N & G & N & V & I & I & H & A & K & Y & T & D & G & N & D & E & W & G\end{array}$ 301 AAGTTGATAACGGTAATGTAATTATTCATGCCAAGTACACTGATGGTAATGATGAATGGG $\begin{array}{lllllllllllllllllllll}102 & D & T & V & E & R & K & R & T & V & K & V & P & E & N & V & D & A & E & K & M\end{array}$ 361 GGGATACTGTTGAACGAAAAAGGACCGTCAAGGTTCCAGAGAATGTTGATGCTGAGAAAA $\begin{array}{lllllllllllllllllllll}122 & H & S & F & M & R & S & D & G & T & M & V & L & E & A & P & Y & L & H & P & E\end{array}$ 421 TGCACAGCTTCATGAGATCAGATGGTACTATGGTATTAGAAGCCCCATACCTTCATCCAG $\begin{array}{lllllllllllllllllllll}142 & \text { E } & R & Q & I & Q & V & V & P & H & E & G & G & A & L & V & S & S & D & S & H\end{array}$ 481 AGGAGAGACAAATACAAGTTGTACCACATGAAGGAGGTGCCTTAGTGTCAAGTGATAGTC $\begin{array}{lllllllllllllllllllll}162 & S & N & L & M & K & F & N & V & E & N & F & R & P & E & E & V & K & V & S & C\end{array}$ 541 ACAGCAACTTGATGAAATTCAATGTTGAAAATTTCCGACCAGAGGAGGTTAAAGTGTCGT $\begin{array}{lllllllllllllllllllll}182 & K & D & G & I & L & T & V & Q & G & E & K & Q & R & S & E & D & G & H & E & I\end{array}$ 601 GTAAGGATGGAATATTGACAGTCCAAGGAGAAAAACAGAGGTCTGAAGATGGTCATGAAA $\begin{array}{lllllllllllllllllllll}202 & R & E & S & F & W & R & Q & M & T & V & P & R & S & V & D & G & K & N & I & E\end{array}$ 661 TACGAGAGTCATTCTGGCGTCAGATGACAGTTCCACGATCTGTGGATGGAAAGAATATTG $\begin{array}{lllllllllllllllllllll}222 & C & L & K & D & E & E & G & N & L & T & I & R & A & P & V & V & E & D & V & E\end{array}$ 721 AATGCTTGAAAGATGAGGAAGGAAATCTTACTATTCGTGCACCAGTTGTTGAAGATGTTG

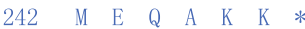

781 AAATGGAACAAGCCAAAAAATAAATCCAGATTTGACTGTCCAAGTCACAATAGCGGATTT 841 TAGACTATACTTTTGAACTTGATTACATTTTTGTAGTCAACATTCTGTCTATTGTGATTG 901 TTTTTGCAATATTGACCAATCATTTGATGTTTCTCATACTGTCAGTAATTTAAAAAAAAA 961 AAAAAAAAAAAAAAAAAAAAAAAAAAAA

Fig.1 The cDNA and deduced amino acid MgsHSP22 (a) and MgsHSP24.1 (b) sequences

The nucleotide and amino acids are numbered along the left margin. The start and stop codons are in bold. and MgsHSP24.1 amino acid sequence C-termini.

The deduced MgsHSP22 amino acid sequence was highly homologous to that of Venerupis philippinarum (ACU83231.1, 61.7\% identity), Bombyx mori (NP_001036985.1，40.1\% identity), Pteromalus puparum (ACO57620.1, 37.8\% identity), and Caenorhabditis elegans (AAA68804.1, 31.2\% identity) sHSP22s (Fig.S1a). However, the deduced MgsHSP24.1 amino acid sequence displayed relatively low identity with its counterparts in other species (Fig.S1b). For example, it shared 37\% identity with Crassostrea gigas sHsp (EKC27011.1), 37\% to Danio rerio sHSP25 (AAV97950.1), and 36\% to Carassius auratus sHSP27 (BAE93468.1).

\subsection{Phylogenetic analysis}

To estimate the evolutionary relationship of the two MgsHsps, two phylogenetic trees were constructed by the neighbor-joining method (Fig.2). MgsHSP22 clustered with Venerupis philippinarum sHSP22, Caenorhabditis elegans sHSP25, Pteromalus puparum sHsp, and Bombyx mori sHSP21.4, forming the invertebrate group (Fig.2a). MgsHSP24.1 formed a common branch with Crassostrea gigas sHsp (99\% bootstrap percentage) (Fig.2b). It then formed the invertebrate group with Venerupis philippinarum sHSP22, Brachionus ibericus sHSP27, Gastrophysa atrocyanea sHSP23, Drosophila buzzatii sHSP27, Tribolium castaneum sHSP21, and Hydra magnipapillata sHsp. The relationships displayed in the phylogenic trees were in good agreement with traditional taxonomy.

\subsection{Tissue distribution of MgsHSP22 and MgsHSP24.1}

The tissue distribution of the MgsHsps transcripts was analyzed by real-time RT-PCR. The MgsHSP22 transcript was predominantly detected in muscle tissue, and moderately expressed in the mantle and gonad, while much lower expression was observed in the gills, hepatopancreas, and hemocytes (Fig.3a). In regards to MgsHSP24.1, the highest expression level was observed in the gonad tissue, and the lowest in the hemocytes (Fig.3b).

\subsection{MgsHSP22 and MgsHSP24.1 mRNAexpression profiles in response to $\mathrm{Cd}$ exposure}

MgsHSP22 and MgsHSP24.1 transcript expression patterns in the hepatopancreas of mussels exposed to 

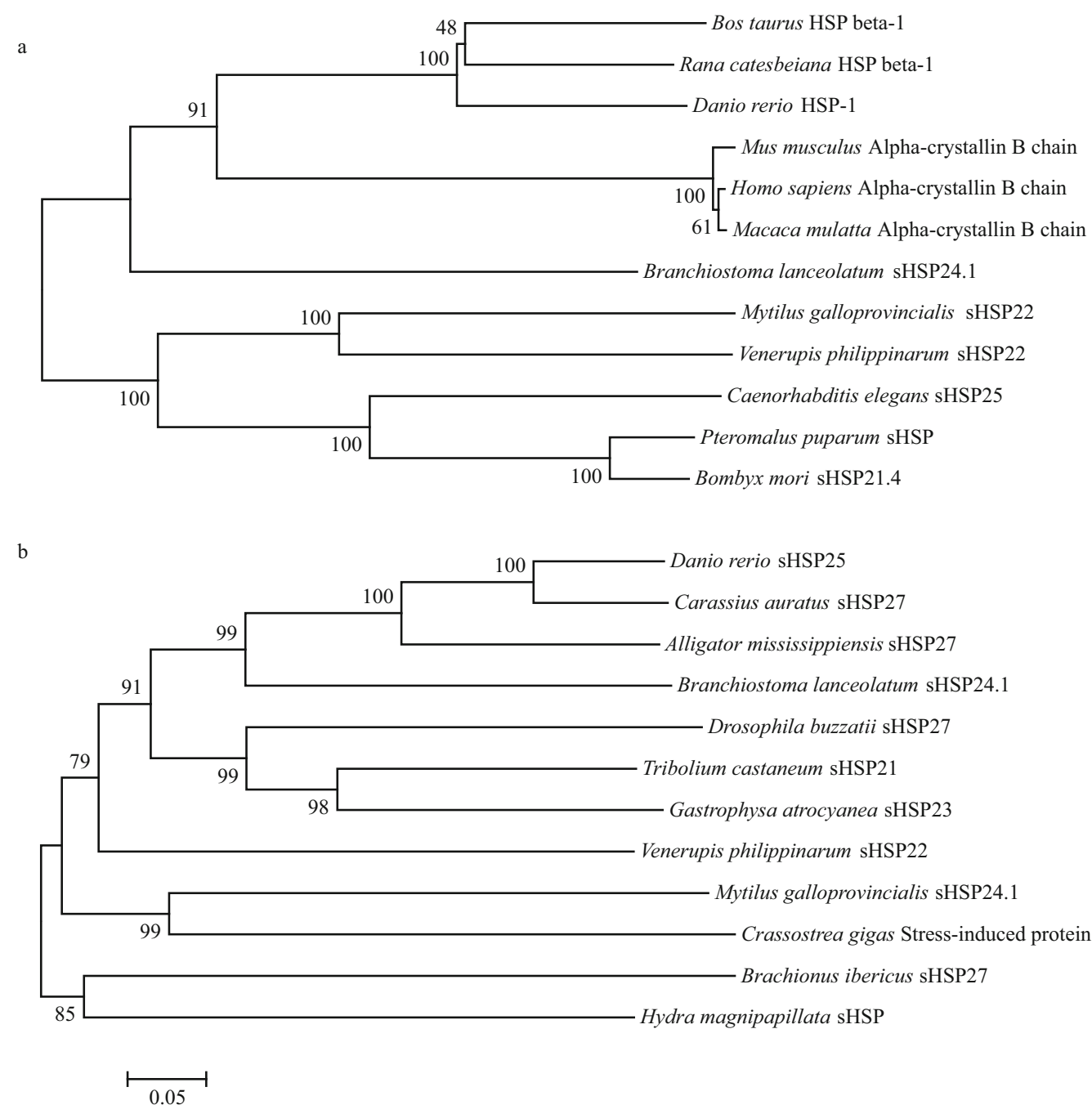

Fig.2 The sHSP22 (a) and sHSP24.1 (b) phylogenetic trees based on the amino acid sequences of sHsp family members by the neighbor-joining method

Bootstrap support values for the NJ tree are shown at the nodes (1 000 replicates). The sequences used here were retrieved from GenBank as follows: Bos Taurus HSP beta-1 (NP_001020740.1), Rana catesbeiana HSP beta-1 (ACO51783.1), Danio rerio HSP-1(CAM12245.1), Mus musculus alpha-crystallin B chain (NP 034094.1), Homo sapiens alpha-crystallin B chain (NP 001876.1), Macaca mulatta alpha-crystallin B chain (XP 001106498.1), Branchiostoma lanceolatum sHSP24.1 (CAE83570.1), Venerupis philippinarum sHSP22 (ACU83231.1), Caenorhabditis elegans sHSP25 (AAA68804.1), Pteromalus puparum sHsp (ACO57620.1), and Bombyx mori sHSP21.4 (NP_001036985.1) for MgsHSP22; Danio rerio sHSP25 (AAV97950.1), Carassius auratus sHSP27 (BAE93468.1), Alligator mississippiensis sHSP27 (BAF94137.1), Branchiostoma lanceolatum sHSP24.1 (CAE83570.1), Drosophila buzzatii sHSP27 (ABX80641.1), Tribolium castaneum sHSP21 (XP 973442.1), Gastrophysa atrocyanea sHSP23 (BAD91165.1), Venerupis philippinarum sHSP22 (ACU83232.1), Crassostrea gigas sHsp (EKC27011.1), Brachionus ibericus sHSP27 (ADR79277.1), and Hydra magnipapillata sHsp (XP_002156113.1) for MgsHSP24.1.

Cd are shown in Fig.4. MgsHSP22 mRNA expression was significantly down-regulated and dropped to $0.2-$ fold $(P<0.01)$ that of the control group following exposure to $5 \mu \mathrm{g} / \mathrm{L} \mathrm{Cd}^{2+}$ for $24 \mathrm{~h}$. As time progressed, the expression level recovered to original levels at $24 \mathrm{~h}$ and $48 \mathrm{~h}$ post exposure. However, when $\mathrm{Cd}$ concentration was increased to $50 \mu \mathrm{g} / \mathrm{L}$, no statistically significant fluctuation in MgsHSP22 expression $(P>0.05)$ was detected during the exposure period.

As for MgsHSP24.1, a significant decrease in the expression level (0.5- and 0.6-fold that of the control,
$P<0.05$ ) was observed at $24 \mathrm{~h}$ and $48 \mathrm{~h}$ in the $5 \mu \mathrm{g} / \mathrm{L}$ $\mathrm{Cd}^{2+}$ treated group. After that, the expression level almost recovered to the original level at $96 \mathrm{~h}$. For the high dose $(50 \mu \mathrm{g} / \mathrm{L})$ Cd-exposed samples, the MgsHSP24.1 expression level decreased significantly to 0.4 -fold that of the control group $(P<0.01)$ at $48 \mathrm{~h}$, and then rose slightly at $96 \mathrm{~h}$.

\subsection{Antioxidant enzyme activity in response to $\mathrm{Cd}$ stress}

As shown in Fig.5, Cd had a significant effect on antioxidant enzyme activity in the $M$. galloprovincialis 

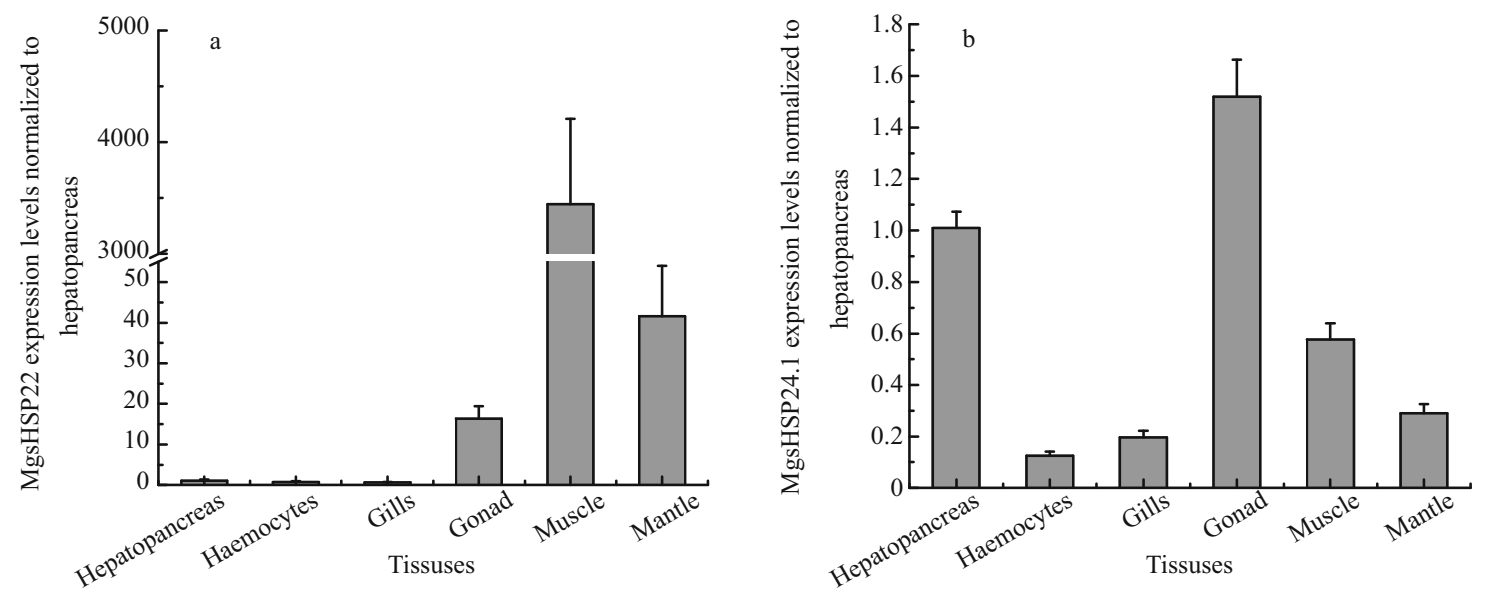

Fig.3 Tissue distribution of the MgsHSP22 (a) and MgsHSP24.1 (b) transcripts as measured by SYBR Green RT-PCR

Transcript levels in the hemocytes, gills, gonad, muscle, and mantle were normalized to that of hepatopancreas. Vertical bars represent the means $\pm \mathrm{SE}(n=6)$.

hepatopancreas. GPx activity attained its peak level after $24 \mathrm{~h}$ exposure to both $\mathrm{Cd}^{2+}$ concentrations $(P<0.01$ and 0.05 , respectively) (Fig.5a). As for CAT, activity increased significantly $(P<0.05)$ at both 24 and $48 \mathrm{~h}$ after $5 \mu \mathrm{g} / \mathrm{L} \mathrm{Cd}^{2+}$ exposure. However, there was no significant alteration in CAT activity during the $50 \mu \mathrm{g} / \mathrm{L} \mathrm{Cd^{2+ }}$ exposure treatment (Fig.5c). Moreover, SOD activity was not significantly affected throughout the experiment (Fig.5b).

\section{DISCUSSION}

In this study, the cDNAs encoding MgsHSP22 and MgsHSP24.1 were identified from $M$. galloprovincialis. The $\alpha$-crystallin domains in the MgsHSP22 and MgsHSP24.1 C-termini confirmed that they belong to the $\alpha$-crystallin-sHsp superfamily. The high homology of MgsHSP22 and relatively low identity of MgsHSP24.1 with their counterparts in other species was in accordance with the inference that sHsp homology varies from between $20 \%$ in remote members to $60 \%$ in closely related members of the sHsp family (Berengian et al., 1999).

sHsp transcript tissue distribution has been reported in many vertebrates and invertebrates. In the present study, MgsHSP22 transcript expression was predominantly observed in $M$. galloprovincialis muscle tissue. This result is in agreement with that of Benndorf et al. (2001), who reported that most members of the mammalian sHsp family (e.g. HSP22), which are abundant in muscles, play a role in muscle function and the maintenance of muscle integrity. A similar result was also observed in sHsp tissue expression in other organisms. For example,
HSP22 in Argopecten irradians was predominantly expressed in the heart and muscle (Zhang et al., 2010). In addition, the MgsHSP24.1 transcript was predominantly detected in $M$. galloprovincialis gonads, indicating that sHSP24.1 participates in development and differentiation regulation. Four Drosophila HSP27 isoforms are constitutively expressed in the testes and two others in the ovaries (Marin et al., 1996). Certain human sHsps are specifically expressed in the testes where they play a crucial role in sperm development (Kappé et al., 2003), and pig HspB9 and HspB10 are testis-specific (Verschuure et al., 2003).

Evidence accumulated to date indicates that environmental contaminants can adversely affect the normal physiological functions in marine organisms. As a major toxic metal in seawater, $\mathrm{Cd}^{2+}$ is responsible for many toxic effects. For example, $\mathrm{Cd}^{2+}$ can induce the production of ROS, e.g., superoxide radical $\left(\mathrm{O}^{-2}\right)$, hydrogen peroxide $\left(\mathrm{H}_{2} \mathrm{O}_{2}\right)$, hydroxyl radical $\left(\mathrm{HO}^{-}\right)$, and singlet oxygen $\left({ }^{1} \mathrm{O}_{2}\right)$, and promote oxidative stress in various organisms (Almeida et al., 2002; Basha and Rani, 2003; Gao et al., 2007).

As the first line of defense against ROS, SOD eliminates the superoxide radical $\left(\mathrm{O}^{-2}\right)$ by catalyzing it to hydrogen peroxide $\left(\mathrm{H}_{2} \mathrm{O}_{2}\right)$, then GPx and CAT catalyze the conversion of hydrogen peroxide $\left(\mathrm{H}_{2} \mathrm{O}_{2}\right)$ to water (Basha and Rani, 2003; Pan and Zhang, 2006). Increased SOD, CAT, and GPx activity have been reported in Charybdis japonica and Pinctada fucata gills hepatopancreas tissues after cadmium and copper exposure, respectively (Jing et al., 2006; Pan and Zhang, 2006). In the present study, no significant difference in SOD activity after $\mathrm{Cd}$ exposure was 

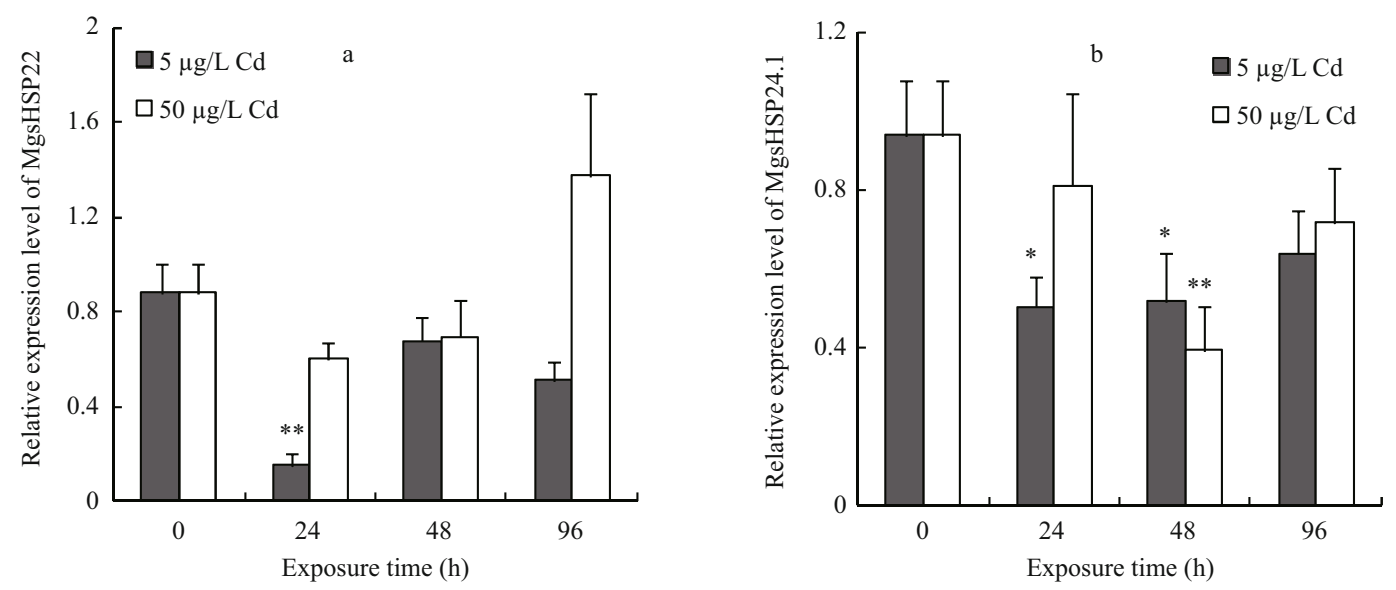

Fig.4 The MgsHSP22 (a) and MgsHSP24.1 (b) mRNA expression levels in mussels exposed to $5 \mu \mathrm{g} / \mathrm{L}$ and $50 \mu \mathrm{g} / \mathrm{L} \mathrm{Cd^{2+ }}$ The values shown are means \pm SE $(n=6)$. Significant differences $(P<0.05)$ and ** highly significant differences $(P<0.01)$.
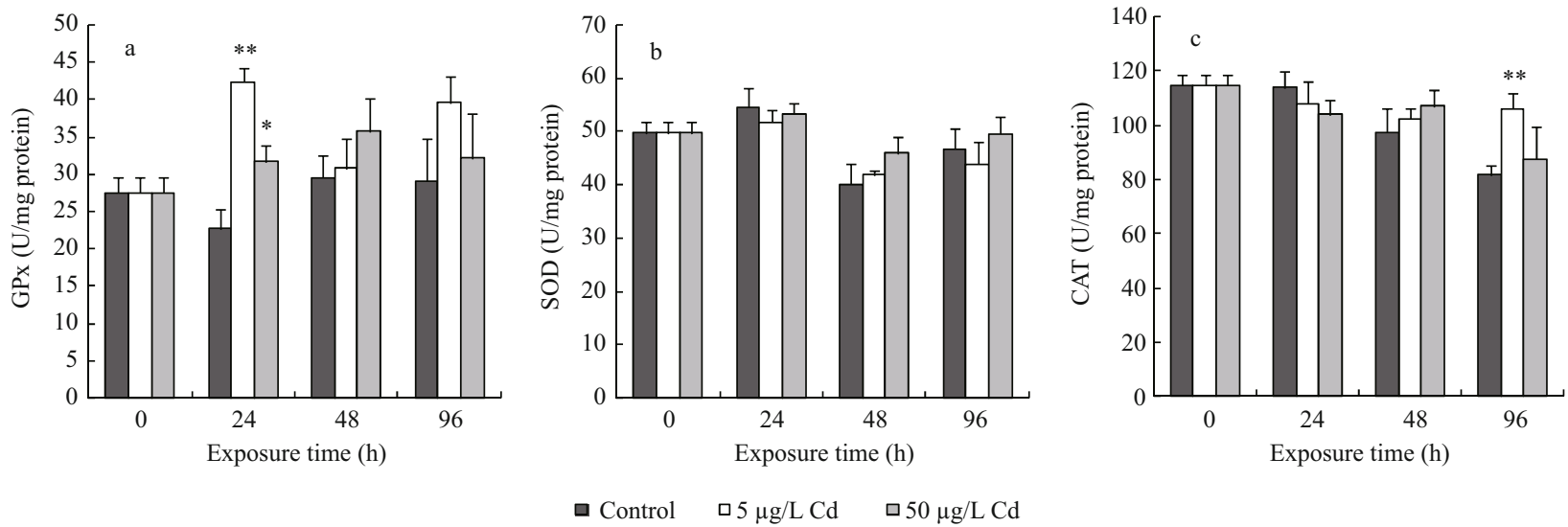

Fig.5 Effects of $\mathrm{Cd}^{2+}$ exposure on GPx (a), CAT (b), and SOD (c) activity in the M. galloprovincialis hepatopancreas Vertical bars represent the means $\pm \operatorname{SE}(n=6)$ * Significant differences $(P<0.05)$ and $* *$ highly significant differences $(P<0.01)$.

observed; this might be because the initial sampling time was delayed. We propose that SOD activity in mussels is mobilized to scavenge the superoxide radical $\left(\mathrm{O}^{-2}\right)$ during the early stages of exposure, and is then restored to normal levels after an exposure time of $24 \mathrm{~h}$. Significant increases in GPx activity at $24 \mathrm{~h}$ and CAT activity at 24 and $48 \mathrm{~h}$ were recorded. This might be the result of the production of $\mathrm{H}_{2} \mathrm{O}_{2}$ from $\mathrm{O}^{-2}$ dismutated by SOD activity in the hepatopancreas. Overall, the three antioxidant enzymes (SOD, GPx, and CAT) in the $M$. galloprovincialis hepatopancreas performed differently after exposure to two $\mathrm{Cd}$ concentrations at different exposure times, and could therefore be used as biomarkers in evaluating the toxicity of $\mathrm{Cd}$ to $M$. galloprovincialis. However, further study is required to validate this.

The cytoprotective effect of sHsp expression has been observed in cells exposed to oxidative stress
(Huot et al., 1996; Mehlen et al., 1996; Preville et al., 1999; Zhang et al., 2010). For example, HSP32 expression was regulated by cellular glutathione against free radical-induced cell damage during neurodegeneration (Calabrese et al., 2008). HSP27 expression can modulate the expression and/or the activity of enzymes involved in the ROS-glutathione pathway (Arrigo et al., 2002). In RPE (retinal pigment epithelium) cells, $\alpha$-crystallin overexpression with increased GSH levels protects cells from apoptosis induced by oxidative stress (Parameswaran et al., 2009). Furthermore, a direct positive correlation between $\alpha$ A-crystallin and GSH was detected in lens epithelial cells, where the absence of $\alpha \mathrm{A}$-crystallin was associated with decreased GSH levels (Kannan et al., 2001). In the present study, MgsHSP22 and MgsHSP24.1 transcript expression both decreased after $\mathrm{Cd}^{2+}$ exposure, while increased GPx activity was observed after $24 \mathrm{~h}$ of $\mathrm{Cd}^{2+}$ exposure. This phenomenon 
might be related to the reduction of GSH, which was used by GPx to detoxify $\mathrm{H}_{2} \mathrm{O}_{2}$ (Saito et al., 2006). Relatively higher GPx activity might lead to lower GSH levels in the $5 \mu \mathrm{g} / \mathrm{L} \mathrm{Cd}^{2+}$-groups compared with that in $50 \mu \mathrm{g} / \mathrm{L} \mathrm{Cd}^{2+}$-groups (Saito et al., 2006), which could explain the relatively higher sHsps in the 50 $\mu \mathrm{g} / \mathrm{L}$ Cd-groups (Kannan et al., 2001). In addition, this phenomenon was in line with the inverted U-shaped model (a low dose of stimulation and high dose of inhibition) in toxicology (Calabrese, 2003; Calabrese, 2004). Zhang et al. (2011) reported a similar hormesis phenomenon in Venerupis philippinarum treated with $\mathrm{Cu}$ and $\mathrm{Cd}$ at concentrations of 10,20 , and $40 \mu \mathrm{g} / \mathrm{L}$. Further research is required to evaluate MgsHSP22 and 24.1 as biomarkers for oxidative stress induced by $\mathrm{Cd}^{2+}$-exposure in $M$. galloprovincialis.

\section{CONCLUSION}

In this study, the full-length cDNAs of two small heat shock proteins were identified from $M$. galloprovincialis. Both transcripts were downregulated in the hepatopancreas after $\mathrm{Cd}^{2+}$ exposure, and increased GPx and CAT activity was observed in response to $\mathrm{Cd}^{2+}$ stress. These results suggest that MgsHSP22 and MgsHSP24.1 transcript expression and GPx and CAT activity could potentially be used as biomarkers in response to $\mathrm{Cd}$ stress in $M$. galloprovincialis; however, further evaluation is required.

\section{References}

Almeida J, Diniz Y, Marques S, Faine L, Ribas B, Burneiko R, et al. 2002. The use of the oxidative stress responses as biomarkers in Nile tilapia (Oreochromis niloticus) exposed to in vivo cadmium contamination. Environment International, 27: 673-679.

Arrigo A P, Paul C, Ducasse C, Sauvageot O, Kretz-Remy C. 2002. Small stress proteins: modulation of intracellular redox state and protection against oxidative stress. Progress in Molecular and Subcellar Bioligy, 28: 171184.

Arrigo A P. 2001. Hsp27: novel regulator of intracellular redox state. Iubmb Life, 52: 303-307.

Basha P S, Rani A U. 2003. Cadmium-induced antioxidant defense mechanism in freshwater teleost Oreochromis mossambicus (Tilapia). Ecotoxicology and Environmental Safety, 56: 218-221.

Benndorf R, Sun X, Gilmont R R, Biederman K J, Molloy M P, Goodmurphy C W et al. 2001. HSP22, a new member of the small heat shock protein superfamily, interacts with mimic of phosphorylated HSP27 (3DHSP27). Journal of Biological Chemistry, 276: 26 753-26 761.
Berengian A R, Parfenova M, Mchaourab H S. 1999. Sitedirected spin labeling study of subunit interactions in the $\alpha$-crystallin domain of small heat-shock proteins. Journal of Biological Chemistry, 274: 6 305-6 314.

Bradford M. 1976. A rapid and sensitive method for the quantification of microgram quantities of protein utilizing the principle of protein-dye binding. Analytical Biochemistry, 72: 248-254.

Calabrese E J. 2003. The maturing of hormesis as a credible dose-response model. Nonlinearity in Biology, Toxicology, and Medicine, 1: 319-343.

Calabrese E J. 2004. Hormesis: a revolution in toxicology, risk assessment and medicine. EMBO Reports, 5: S37-S40.

Calabrese V, Signorile A, Cornelius C, Mancuso C, Scapagnini G, Ventimiglia B et al. 2008. Practical approaches to investigate redox regulation of heat shock protein expression and intracellular glutathione redox state. Methods in Enzymology, 441: 83-110.

Caspers G J, Leunissen J A M, de Jong W W. 1995. The expanding small heat-shock protein family, and structure predictions of the conserved "a-Crystallin Domain". Journal of Molecular Evolution, 40: 238-248.

Chowdary T K, Raman B, Ramakrishna T, Mohan Rao C. 2004. Mammalian Hsp22 is a heat-inducible small heatshock protein with chaperone-like activity. Biochemical Journal, 381: 379-387.

Franck E, Madsen O, Van Rheede T, Ricard G, Huynen M A, De Jong W W. 2004. Evolutionary diversity of vertebrate small heat shock proteins. Journal of Molecular Evolution, 59: 792-805.

Gao Q, Song L S, Ni D J, Wu L T, Zhang H, Chang Y Q. 2007. cDNA cloning and mRNA expression of heat shock protein 90 gene in the haemocytes of Zhikong scallop Chlamys farreri. Comparative Biochemistry and Physiology Part B: Biochemistry and Molecular Biology, 147: 704-715.

Guo S, Wharton W, Moseley P, Shi H. 2007. Heat shock protein 70 regulates cellular redox status by modulating glutathione-related enzyme activities. Cell Stress \& Chaperones, 12: 245-254.

Gusev N, Bogatcheva N, Marston S. 2002. Structure and properties of small heat shock proteins (sHsp) and their interaction with cytoskeleton proteins. Biochemistry (Moscow), 67: 511-519.

Haslbeck M. 2002. sHsps and their role in the chaperone network. Cellular and Molecular Life Sciences, 59: 1 6491657.

Huot J, Houle F, Spitz D R, Landry J. 1996. HSP27 phosphorylation-mediated resistance against actin fragmentation and cell death induced by oxidative stress. Cancer Research, 56: 273-279.

Järup L. 2003. Hazards of heavy metal contamination. British Medical Bulletin, 68: 167-182.

Jena K, Verlecar X, Chainy G. 2009. Application of oxidative stress indices in natural populations of Perna viridis as biomarker of environmental pollution. Marine Pollution Bulletin, 58: 107-113. 
Jing G, Li Y, Xie L P, Zhang R Q. 2006. Metal accumulation and enzyme activities in gills and digestive gland of pearl oyster (Pinctada fucata) exposed to copper. Comparative Biochemistry and Physiology Part C: Toxicology \& Pharmacology, 144: 184-190.

Kannan R, Ouyang B, Wawrousek E, Kaplowitz N, Andley U P. 2001. Regulation of GSH in alphaA-expressing human lens epithelial cell lines and in alphaA knockout mouse lenses. Investigative Ophthalmology \& Visual Science, 42: 409-416.

Kappé G, Franck E, Verschuure P, Boelens W C, Leunissen J A M, De Jong W W. 2003. The human genome encodes 10 $\alpha$-crystallin-related small heat shock proteins: HspB1-10. Cell Stress \& Chaperones, 8: 53-61.

Kavun V Y, Shulkin V, Khristoforova N. 2002. Metal accumulation in mussels of the Kuril Islands, north-west Pacific Ocean. Marine Environmental Research, 53: 219226.

Klemenz R, Gehring W J. 1986. Sequence requirement for expression of the Drosophila melanogaster heat shock protein hsp22 gene during heat shock and normal development. Molecular and Cellular Biology, 6: 2 011-2 019.

Kozawa O, Matsuno H, Niwa M, Hatakeyama D, Kato K, Uematsu T. 2001. $\alpha$ B-crystallin, a low-molecular-weight heat shock protein, acts as a regulator of platelet function. Cell Stress \& Chaperones, 6: 21-28.

Lewis S, Handy R, Cordi B, Billinghurst Z, Depledge M H. 1999. Stress proteins (HSP's): methods of detection and their use as an environmental biomarker. Ecotoxicology, 8: $351-368$.

Lindquist S. 1986. The heat shock response. Annual Review of Genetics, 22: 631-677.

Liu H C, Chen H H, Jing J, Ma X F. 2012. Cloning and characterization of the HSP90 beta gene from Tanichthys albonubes Lin (Cyprinidae): effect of copper and cadmium exposure. Fish Physiology and Biochemistry, 38: 745-756.

Liu X L, Zhang L B, You L P, Yu J B, Zhao J M, Li L Z et al. 2011. Differential toxicological effects induced by mercury in gills from three pedigrees of Manila clam Ruditapes philippinarum by NMR-based metabolomics. Ecotoxicology, 20: 177-186.

Livak K J, Schmittgen T D. 2001. Analysis of relative gene expression data using real-time quantitative PCR and the $2^{-\Delta \Delta C t}$ method. Methods, 25: 402-408.

Locke M, Noble E G, Atkinson B G. 1991. Inducible isoform of HSP70 is constitutively expressed in a muscle fiber type specific pattern. American Journal of PhysiologyCell Physiology, 261: C774-C779.

Marin R, Landry J, Tanguay R M. 1996. Tissue-Specific posttranslational modification of the small heat shock protein HSP27 in Drosophila. Experimental Cell Research, 223: 1-8.

Mayer M P, Bukau B. 2005. Hsp70 chaperones: cellular functions and molecular mechanism. Cellular and
Molecular Life Sciences, 62: 670-684.

Mehlen P, Préville X, Kretz-Remy C, Arrigo A P. 1996. Human hsp27, Drosophila hsp27 and human $\alpha \mathrm{B}$-crystallin expression-mediated increase in glutathione is essential for the protective activity of these protein against TNF $\alpha$ induced cell death. Embo. Journal, 15: 2 695-2 706.

Ooie T, Takahashi N, Saikawa T, Nawata T, Arikawa M, Yamanaka K et al. 2001. Single oral dose of geranylgeranylacetone induces heat-shock protein 72 and renders protection against ischemia/reperfusion injury in rat heart. Circulation, 104: 1 837-1 843.

Orbea A, Dariush Fahimi H, Cajaraville M P. 2000. Immunolocalization of four antioxidant enzymes in digestive glands of mollusks and crustaceans and fish liver. Histochemistry and Cell Biology, 114: 393-404.

Pan L Q, Zhang H X. 2006. Metallothionein, antioxidant enzymes and DNA strand breaks as biomarkers of $\mathrm{Cd}$ exposure in a marine crab, Charybdis japonica. Comparative Biochemistry and Physiology Part C: Toxicology \& Pharmacology, 144: 67-75.

Parameswaran S, Spee C, Ryan S J, Kannan R, Hinton D R. 2009. Decreased cellular glutathione (GSH) and increased GSH efflux in \{alpha\}-crystallin knockout retina. Investigative Ophthalmology \& Visual Science, 50: E-Abstract 1831.

Pipe R K, Coles J A. 1995. Environmental contaminants influencing immunefunction in marine bivalve molluscs. Fish \& Shellfish Immunology, 5: 581-595.

Preville X, Salvemini, F, Giraud S, Chaufour S, Paul C, Stepien $\mathrm{G}$ et al. 1999. Mammalian small stress proteins protect against oxidative stress through their ability to increase glucose-6-phosphate dehydrogenase activity and by maintaining optimal cellular detoxifying machinery. Experimental Cell Research, 247: 61-78.

Raghavan N, Ghosh I, Eisinger W S, Pastrana D, Scott A L. 1999. Developmentally regulated expression of a unique small heat shock protein in Brugia malayi. Molecular and Biochemical Parasitology, 104: 233-246.

Richardson B J, Mak E, De Luca-Abbott S B, Martin M, McClellan K, Lam P K S. 2008. Antioxidant responses to polycyclic aromatic hydrocarbons and organochlorine pesticides in green-lipped mussels (Perna viridis): do mussels "integrate" biomarker responses? Marine Pollution Bulletin, 57: 503-514.

Roccheri M C, Agnello M, Bonaventura R, Matranga V. 2004. Cadmium induces the expression of specific stress proteins in sea urchin embryos. Biochemical and Biophysical Research Communications, 321: 80-87.

Saito Y, Nishio K, Ogawa Y, Kimata J, Kinumi T, Yoshida Y et al. 2006. Turning point in apoptosis / necrosis induced by hydrogen peroxide. Free Radical Research, 40: 619-630.

Shatilina Z M, Bedulina D S, Protopopova M V, Pavlichenko V V, Pobezhimova T P, Grabelnykh O I et al. 2010. Heat shock proteins in the mechanisms of stress adaptation in Baikal Amphipods and Palaearctic Gammarus lacustris 
Sars II. small HSP Family. Contemporary Problems of Ecology, 3: 449-456.

Sun Y, MacRae T H. 2005. Small heat shock proteins: molecular structure and chaperone function. Cellular and Molecular Life Sciences, 62: 2 460-2 476.

Trent J D. 1996. A review of acquired thermotolerance, heatshock proteins, and molecular chaperones in archaea. FEMS Microbiology Reviews, 18: 249-258.

Verschuure P, Tatard C, Boelens W C, Grongnet J F, David J C. 2003. Expression of small heat shock proteins HspB2, HspB8, Hsp20 and cvHsp in different tissues of the perinatal developing pig. European Journal of Cell Biology, 82: 523-530.

Waisberg M, Joseph P, Hale B, Beyersmann D. 2003. Molecular and cellular mechanisms of cadmium carcinogenesis.
Toxicology, 192: 95-117.

Wang Q, Wang X M, Wang X Y, Yang H S, Liu B Z. 2010. Analysis of metallotionein expression and antioxidant enzyme activities in Meretrix meretrix larvae under sublethal cadmium exposure. Aquatic Toxicology, 100: 321-328.

Zhang L B, Liu X L, Chen L L, You L, Pei D, Cong M et al. 2011. Transcriptional regulation of selenium-dependent glutathione peroxidase from Venerupis philippinarum in response to pathogen and contaminants challenge. Fish \& Shellfish Immunology, 31: 831-837.

Zhang L, Wang L L, Song L S, Zhao J M, Qiu L M, Dong C H et al. 2010. The involvement of HSP22 from bay scallop Argopecten irradians in response to heavy metal stress. Molecular Biology Reports, 37: 1 763-1 771. 